\title{
Erratum to: Sarcocystis oreamni, n. sp. (Apicomplexa: Sarcocystidae) from the mountain goat (Oreamnos americanus)
}

\author{
Rafael Calero-Bernal $^{1} \cdot$ Erna Van Wilpe ${ }^{2} \cdot$ Kevin White $^{3} \cdot$ Shiv K. Verma ${ }^{1}$. \\ Camila K. Cerqueira-Cézar ${ }^{1}$ • Jitender P. Dubey ${ }^{1}$
}

Published online: 29 October 2015

(C) Springer-Verlag Berlin Heidelberg 2015

Erratum to: Parasitology Research

\section{DOI 10.1007/s00436-015-4644-3}

The addresses of Erna Van Wilpe and Kevin White in the original version of this article were mixed up. Correct affiliations are presented below.

Erna Van Wilpe

Department of Anatomy and Physiology, Faculty of Veterinary Science, University of Pretoria, Onderstepoort 0110, South Africa

Kevin White

Alaska Department of Fish and Game, Division of Wildlife

Conservation, Juneau, AK 99811, USA

The online version of the original article can be found at http://dx.doi.org/ 10.1007/s00436-015-4644-3.

Jitender P. Dubey

jitender.dubey@ars.usda.gov

1 United States Department of Agriculture, Agricultural Research Service, Beltsville Agricultural Research Center, Animal Parasitic Diseases Laboratory, Beltsville, MD 20705-2350, USA

2 Department of Anatomy and Physiology, Faculty of Veterinary Science, University of Pretoria, Onderstepoort 0110, South Africa

3 Alaska Department of Fish and Game, Division of Wildlife Conservation, Juneau, AK 99811, USA 